\title{
IMF: GMO between myopia and scarce credibility
}

\section{Fabrizio Pezzani}

\section{IMF: To be or not to be? That is the question}

A recent Gallup survey on credibility and trust in the US media shows a decline, reaching the lowest point since 1972 when this type of analysis was started; the trust that has diminished by $50 \%$ in recent years is continually fuelled by a media war constituted of false information fake news - that reality quickly denies in a succession of mutual accusations. This figure represents the disconnection between the ruling elites and the real country they do not want to see, ending up not understanding the meaning of history and its teaching on the growth and collapse of societies.

If trust towards the media were extended to financial market analysts they would be desolated, every single day the media report projections, indoctrinations that are denied by the facts; but increasingly surprising is the forecasting game error in which the IMF is specializing, which over time has become a Genetically Modified Organism (GMO) and its institutional aims are totally opposite to what it has become. The myopia of warnings dictated as an inexorable judgement melt in face of the facts, just like snow in the sun, yet seeming to remain incontrovertible and indisputable truth.

Precisely an IMF economist, Prakash Loungani, undertook some interesting research about the accuracy of analysts-economists' forecasts. Using data from a the Consensus Forecasts (published by Consensus Economics), Loungani showed that for over three decades among the 150 recorded recessions only two were predicted, the error rate then rose to $100 \%$ despite continuously updating the forecasting model - but not too much; paradoxically they would have had a greater forecasting probability by relying on the heads or tails of a tossed coin. The projections made are financial and not economic, but finance since completely disengaged currency in 1971 from real and finite values - gold - separating it, in this way, from the emotional world of man, operates in a detached context from reality, creating the idea that socalled "rational" markets accurately interpret the facts.

The following graphs show the vagaries of the forecasts that, perhaps left to the ancient art of haruspicy, would be more reliable: 

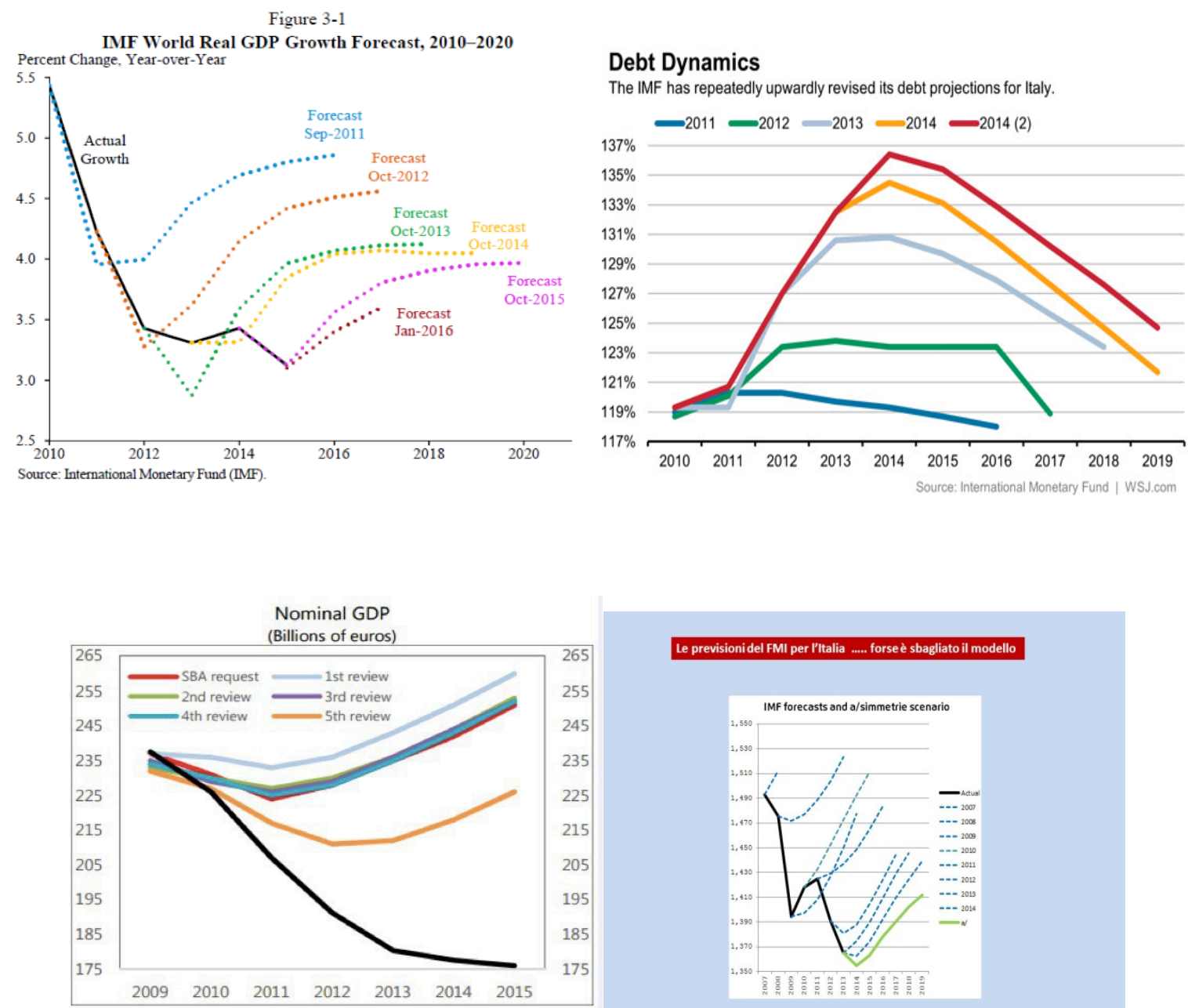

Source: IMF Country Reports and WEO.
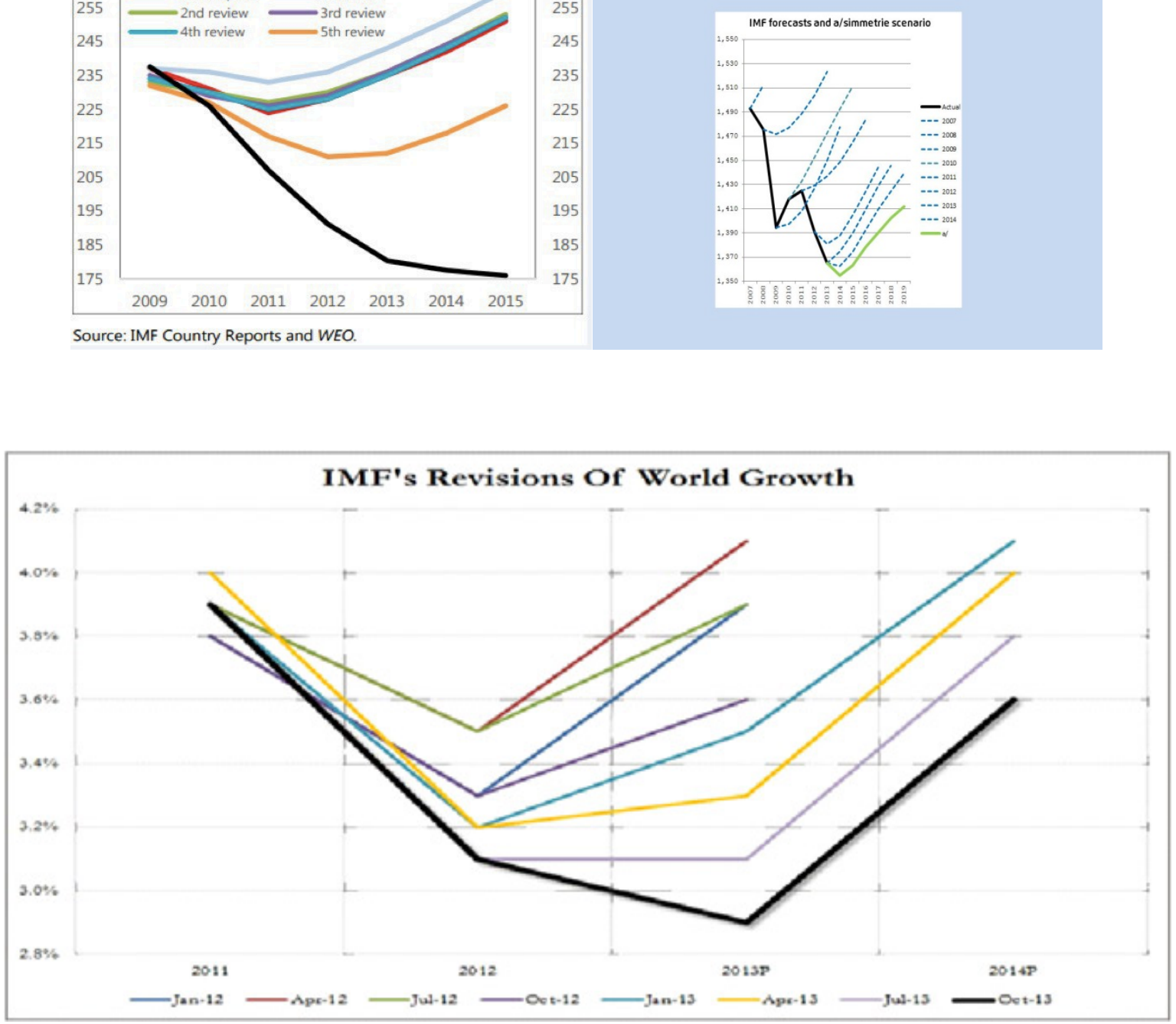

Let us stop here to try to understand why the forecasting models of financial analysts and the IMF have such dramatic predictive performance and cannot function, since they are asymmetric to the reality and presume that reality should be adapted to their astral models while logic clearly suggests the opposite, namely, the models must adapt to the reality. As the great astrophysicist Hawking recently said, "The greatest enemy of knowledge is not 
ignorance, it is the illusion of knowledge".

\section{A deterministic model for a probabilistic world}

Let us try to understand the genesis and the transformation of the IMF from the Keynesian logic that established it to a subordinate organism of a monetarism that is an end in itself and far from the reality that continues to apply a deterministic model, dramatically forgetting that reality, understood as the finite reality in which we live and work, has a probabilistic dimension in which doubt and probability determine a "a dynamic mess of jiggling things " as the great Feynman called it. This crisis has a cultural and non-economic nature and the presumption of wanting the reality to adapt to models and not vice versa is the most evident manifestation of a socio-cultural model that has dominated our world for decades and has in fact failed. In this sense, Ilya Prigogine recalled that: "The problems of time and determinism have remained at the core of Western thought since the pre-Socratics. How can we conceive of human creativity or ethics in a deterministic world? This question reflects a profound contradiction in Western humanistic tradition, which emphasizes the importance of knowledge and objectivity, as well as individual responsibility and freedom of choice as implied by the ideal of democracy.... In fact, we owe to the ancient Greeks two ideals that have since shaped human history. The first is the intelligibility of nature ... The second is the idea of democracy based on the assumption of human freedom, creativity, and responsibility. As long as science led to the description of nature as an automaton, these two ideals were contradictory". We have created with rational finance a dualism alien to the adventure of man in this world and to his very particular mission of creating a world that aspires to the happiness of all in the common good. The IMF contributed with its action-not action to allow all the unlawful behaviours that the US Department of Justice highlighted by condemning the Wall Street investment banks for fraudulent manipulation of the sub-prime that caused the crisis in 2009, condemning S\&P for fraudulent manipulation of the rating, the campaign of Europe assaulted by finance without any obstacle to the raging toxic products that have stripped our reserves starting from Deutsche Bank that still has 60 billion euro in its coffers. In all these dramatic situations where was the IMF? On which side was the IMF ready for austerity measures without regulating - as was its institutional duty - the toxic products that have poisoned us? Where is the IMF now in the face of a mass of endless dollars and cryptocurrencies never seriously condemned? But if it does not carry out its "institutional" supervisory authority and take responsibility, what is the IMF doing and what is it for? Perhaps it is necessary to ask these questions but also to try to provide answers by retracing the history that put it in an asymmetric context to the role for which it was created.

In this sense, the IMF and in a broader sense the financial analysts moving in a shared cultural terrain and never questioned, resemble in a figurative sense the inhabitants of the planet "Laputa" that Gulliver encounters in his fantastic journeys, the author Jonathan Swift in his book "Gulliver's Travels" describes it as inhabited by crazy and ingenious scientists and mathematicians in their own things but totally detached from the real world, of which they understand nothing, alongside and below them the subjects who obey without discussing their ideas in a sort of servile passivity; in this way, even then Swift intended to criticize the academies of the sciences at the time made up of arrogant "scholars" and as presumptuous as inadequate in responding to the real and profound problems of society. The picture that Swift paints in his story represents once again the drama of man always suspended between his drive towards his own prophecy and the stupidity of a game of slaughter; once again: "nihil sub sole novi" (nothing under the sun is new). 


\section{The genesis and abandoned institutional purposes}

The IMF was created in a period of history intended to put back together the pieces of war-torn societies but ended up forgetting the purpose for which it was created. The perhaps desired lack of a redefinition of its role in a dramatically changed monetary context has ended up being the problem and not the solution to the problems for which it was intended, paradoxically complicating them instead.

The IMF was established at Bretton Woods just before the end of the war and formally established on 27 December 1945 when the first and important 29 member states - now 188 subordinated to the dominant oligarchy - signed the founding agreement. Considering its institutional goals, one can begin to understand how distant its actions are from those guidelines. If we look at history, not a great deal of time has passed since then, yet it seems like an eternity ago. In the last 50 years, the world has changed in the spirit that guided the great post-war dreamers, progressively consolidating a rational culture that turned finance and neoliberalism into a purpose cloaked falsely as absolute sacredness. Finance has broken free from the real economy and has become a means of exercising power that stands above others, with an inner end that certainly does not coincide with the common good.

A determinant role in recent years has been played by the IMF that has broken away from the founding guidelines constituted by its statute and even taking a type of neoliberal instead of Keynesian line for which it was designed. Recalling here the "absolute" purposes listed in the IMF Articles of Agreement:

i. To promote international monetary cooperation... consultation and collaboration...

ii. To facilitate the expansion and balanced growth of international trade... contribute to the maintenance of high levels of employment and real income and to the development of the productive resources of all members...

iii. To promote exchange stability... and to avoid competitive exchange depreciation.

iv. To assist in the establishment of a multilateral system of payments... and in the elimination of foreign exchange restrictions which hamper the growth of world trade.

v. To give confidence to members by making the general resources... without resorting to measures destructive of national or international prosperity.

vi. In accordance with the above, to shorten the duration and lessen the degree of disequilibrium...

The Fund shall be guided in all its policies and decisionals by the purposes set forth in this Article.

The current situation is in stark contradiction with the IMF's statute and operations. The definition of these guidelines was agreed in the long negotiations at Bretton Woods that Keynes took part in - who before being an economist was a great social scientist - and unlike modern economists, never erred. The basic problem was the clash between the European and the American culture. The former was the result of centuries of creating utopias but also perpetrating tragedies and awareness of having to combine the social sense with the idea of sustainable development but not guaranteed if not based on the principle of political, social, economic, and financial equilibrium. The profound sense of this culture was the definition of a table with legs that had to be more or less the same height otherwise sooner or later the table topples with everything on it.

This cultural model was founded on the idea that the IMF should be a cooperation fund that individual States could access to keep the economy and society alive. In a certain sense, this idea came to life with the Marshall Plan and relinquishing the war debts of victorious countries 
to Germany, with the exception of Russia; memories tend to be short and selfinterested. Keynes' principle was based on his prior experience of the Treaty of Versailles at the end of World War I that had led to the Weimar Republic's hyperinflation and indeed to the Second World War to erase the wrongs. Keynes followed the work of the great social economist Shacht Hjalmart with a policy based on the real economy and on a sophisticated barter formulation detached from the monetarism that was suffocating the country. Keynes exercised the same care with the great depression in the United States of Roosevelt, saving it from finance that had become oppressive; history had taught him well.

The history of the US instead contributed to entrusting the future to technical development considered in itself an absolute success, and the American negotiator, Harry Dexter White, considered the IMF as a bank that would finance States according to their needs. The difference reflects the different histories of the two countries, the US and UK, the former enjoying considerable credit and gold reserves while the latter had experienced the social risks arising from unemployment. History, when forgotten, always presents the bill, and thus the social and financial collapse of the United States is a kind of nemesis of arrogance and lack of memory; foresight distinguishes us from animals and its absence is always the result of fatal calamities.

The economic "boom" of the post-war period had a considerable effect on the real economy, redesigning a world that had seemed hopeless. These were years of creativity, imagination, and hope, but the historical cycles today are much faster and the time of illusion ended in the early seventies when the US unilaterally declared the end of Bretton Woods and the "gold exchange standard" system. We thus entered the "time of finance" that is strangling us today. The financialization of the real economy and its uncritical deification began in the years when Nixon declared the decoupling of the dollar from the gold standard - 28 printable dollars for every gram of gold - because US lenders who did not trust the dollar money supply wanted to be paid in gold, stripping the country's gold reserves to the bone, as is happening today. Indeed, by refusing to redeem dollars in gold held by other central bank, the Fed destroyed the monetary order established at Bretton Woods. The world suddenly found itself hostage to a floating exchange rate system that radically changed the monetary system based on the dollar into a giant sacred temple of speculation whose priests were cloaked in infallible sacredness. The "petrodollar" operation in this way inaugurated the gradual subjection, of even the IMF, to knowledge based not on correct scientific hypotheses - an unscientific approach as F. von Hayek called it in his acceptance speech for the Nobel Prize in 1974 - yet uncritically endured.

Everything becomes astral money:
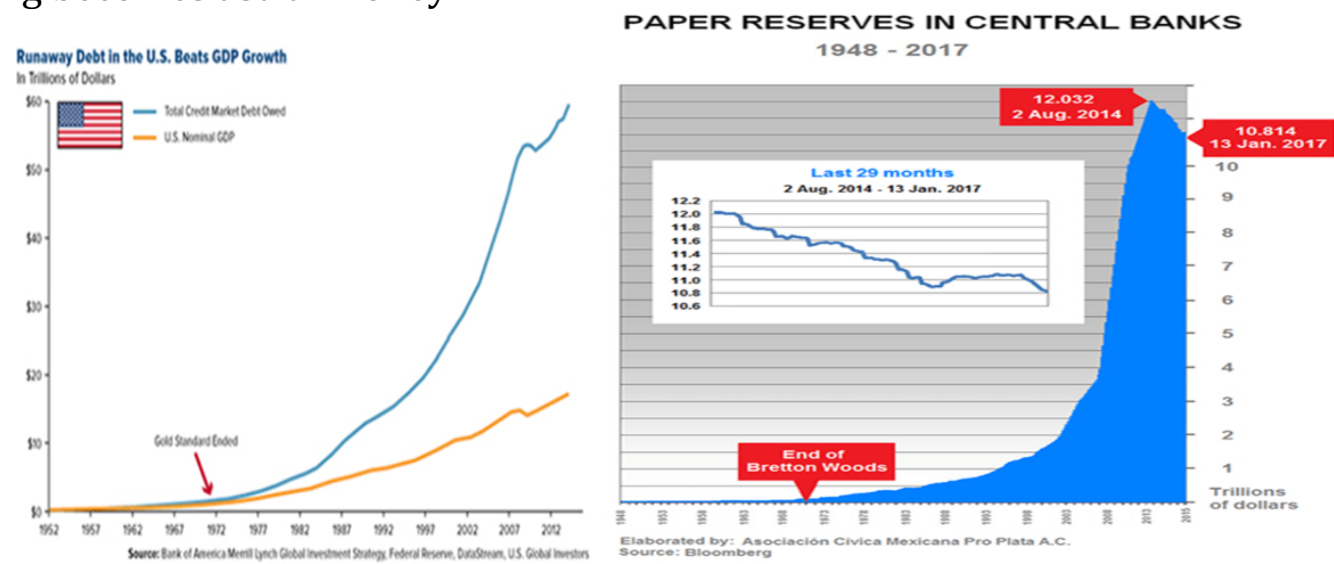


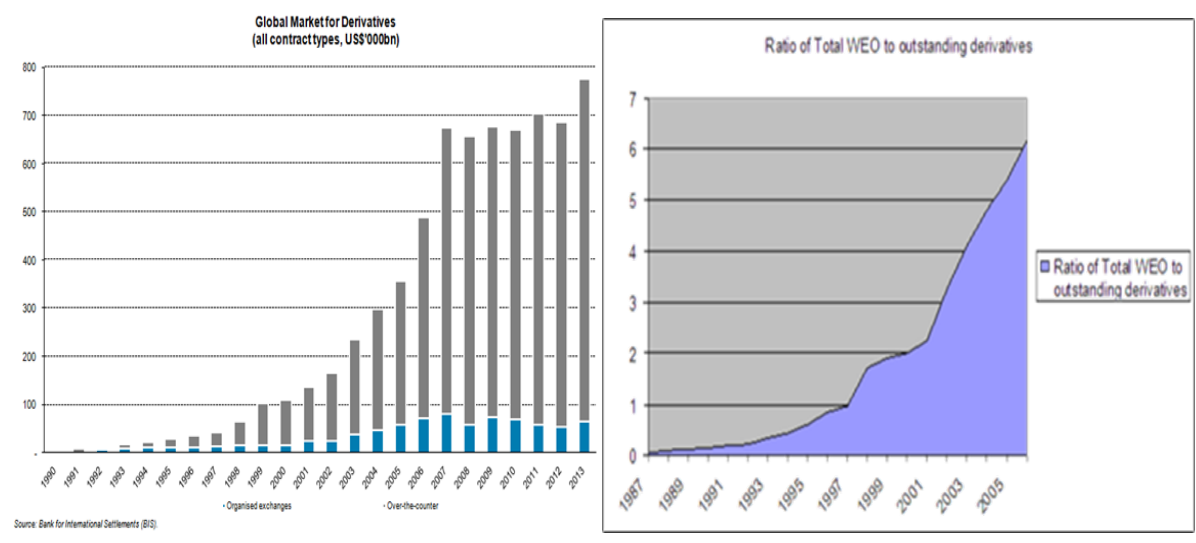

Recalling point (ii): To facilitate the expansion and balanced growth of international trade... contribute to the maintenance of high levels of employment and real income and to the development of the productive resources of all members... (!!!)

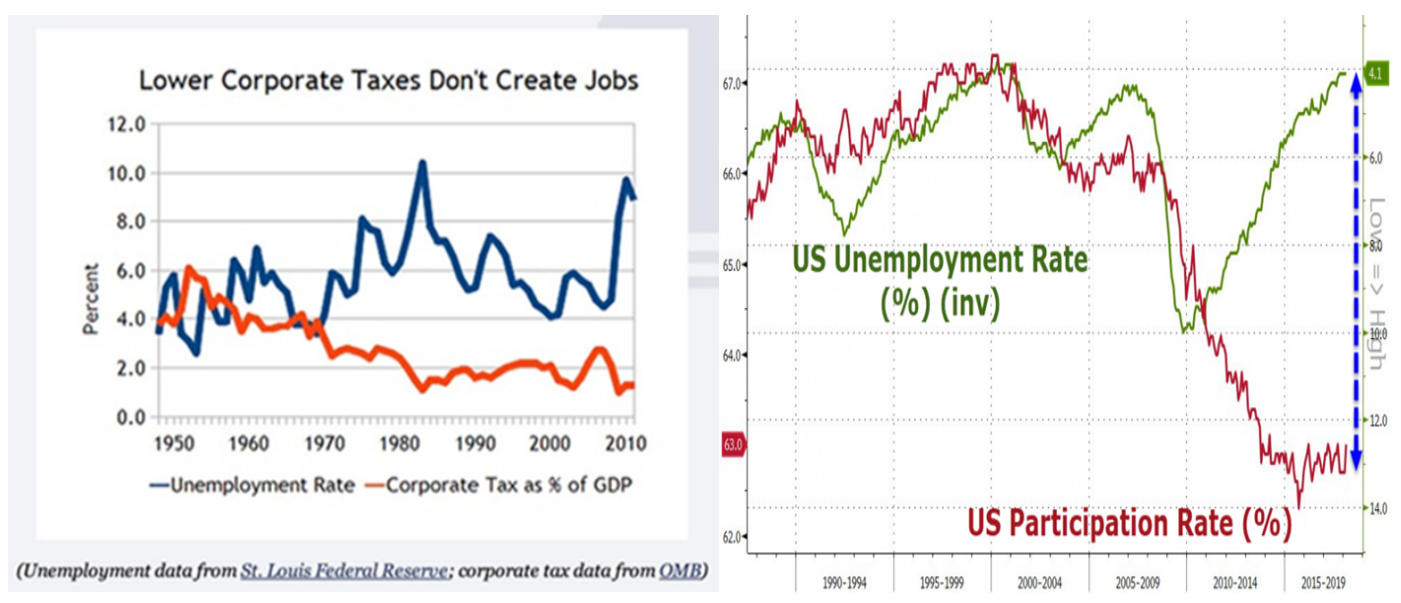

Since then, the economic, financial and social situation has totally changed, while the real economy did not suffer particular deviations up to the delocalization surge; in the early years of the century, finance and money assumed an increasingly important role at all levels. The cycles of financial crises since then, like a financial tsunami, have started to become increasingly deeper and long: we have had the oil shocks, Black Monday, the Internet bubble, Chile, Mexico (the tequila bonds), Argentina (the tango bonds), the "Asian Tigers" (Japan, Thailand, Malaysia, South Korea, Hong Kong ...), the attack on the rouble, the LTCM default (the Long-Term Capital Management of Merton and Scholes awarded the Nobel prize in 1997 for the "rationality of derivatives"), ending with the sub-primes, derivatives, credit default swaps and the magical warehouse of puppeteers who trade nothingness with gold and finance as the "Philosopher's stone". All the drama of sacral finance to no avail, in front of the immense disaster we have the prophets of "omnipotence". The "venerable" Lucas - Nobel in 1995 for rational markets - in 2003 declared to the American Economic Association that the "central problem of depression-prevention has been solved, for all practical purposes". A year later Ben Bernanke who served on the board of the Federal Reserve argued, much as Lucas had, that modern macroeconomic policy had solved the problem of the business cycle - or, more precisely, reduced the problem to the point that it was more of a nuisance than a front-rank issue. Not content, in 2007 Bernanke stated to Congress, "At this juncture, however, the impact on the broader economy and financial markets of the problems in the subprime market seems likely to be contained" in the same way as Paulson who guaranteed that the sub-prime market would not be a danger to the economy as a whole. Greenspan in 1999 totally deregulated 
derivatives and elevated financial speculation by repealing the "Glass Steagall Act" that Roosevelt instigated in 1932 to tie the hands of finance. The current crisis was not caused by natural or unpredictable events but by men like these who with the authority of their positions legitimized a global deception. What responsibilities do these men have in the social and moral degradation that we face? These men dictated the culture and the rules that the IMF has always endured in an unjustifiable subjection to its role as guarantor of the founding principles for human respect.

This flooding of finance and liquidity for its own sake ended up definitively detaching the IMF from reality and making it surf in an aseptic world dominated by currency and becoming its hostage. When the neoliberal model that is completely asymmetric to Keynesian collaborative ideas was affirmed as incontrovertible truth, the IMF detached from that initial idea and began to dictate the rules of a model without remotely bothering to questioning it, and the unregulated market became a dogma and the best solution for the economic development of the poorest countries. The same formula was promoted for everyone even in countries with very different histories and cultures, creating a cultural wasteland where the key to the problem can no longer be found. The IMF has simultaneously become the victim and executioner, unable to understand its purpose. Strauss Kahn had made an attempt on 19 April 2011 and told the Brookings Institution in Washington but they did not allow even a month, as on May 11 he was taken off a plane to Paris and conducted to jail for a crime that on August 21 of that year was declared as non-existent. Today, the IMF seems to be an institution more geared to its own survival than those of the poorest member States and so the principle of collaboration made room for the principle of utility, often only personal but also in a position of subordination to the financial oligarchy; its actions are often linked to those of the Fed.

The indicated but forgotten guidelines were written for an economic system that was rooted in the real economy, but since the fall of the Berlin Wall, the interests of finance, politics, and even the Academy have forced a change of reality and of the genesis of economics that turned into a mathematical game bent toward finance and monetarism without technical or moral limits. Neoliberalism pushed to excess has become dominant and pure power. The new century presented itself with a disaster of enormous proportions and we do not yet know whether and how it will end. The toxic products created by mathematicians, nuclear physicists, statisticians have distanced their world of formulas from the real world and helped justify the means that have become oppressive. The IMF did not resist the disruptive invasion of this cultural model and has moved away from the roots of safeguarding the real economy for which it was established, endorsing acts that result in forms of social and political dislocation. Greece was the first victim of this exercise of power - punishing one to educate all - and we now ask ourselves how it will end. Sooner or later, the problems and designs behind this "Armageddon" will be brought to the centre of the global and social debate.

It seems that the IMF as in Ovid's Metamorphoses will end up like Narcissus who fell in love with his own reflection, punished in this sense by the Nemesis for ignoring the love of the nymph Echo (social justice, we would call it today - author's note). Sentenced to falling in love with his own image, but never being able to hold and touch it, he lets himself die, and the Naiads and Dryads found in his place a flower and gave it his name. I wonder if after these misfortunes the IMF can undergo a metamorphosis turning into a flower of peace and cooperation rather than war, and try to find in the principle of collaboration a new life and rediscover the real mission for which it was intended in that distant 1944 when the disasters of war seemed to convey man towards wisdom, but even this seems to be just a myth. 
Have these international institutions intended to safeguard human dignity been respectful of the purposes for which they were designed and established? Are these institutions guilty of ignoring the demons of finance? In a world where everyone faces the choice of the becoming of man, today, are these institutions and the men who govern them able - in cultural, moral, and independent terms - to face with seriousness and responsibility just decisions in compliance with the mandate assigned them? If this has not been and today is not their role, then their composition must be forcefully rethought. The mistakes require rethinking their structure and the way the institutions function, in the end, however, problems are always and only problems of men, more or less suited to the roles that they have been given.

\section{CONCLUSIONS: "The elite must, in various respects, respond to the court of history for the damage done to man's future"}

"Perhaps it is time to ask, before it is too late, to what extent a "capitalist finance" model and its manipulated instruments such as GDP, as has been stated over the years, is responsible for the damages that have led to the world's fate and to what extent the collective responsibilities have not worked by letting themselves be led towards the disorder of unregulated markets. When a cultural model is affirmed and legitimized at the global level by both the Academy and politics, by force and against the scientific evidence demonstrating its unfoundedness, and leading to social dramas that expunge the declarations of universal human rights, we must ask ourselves what has gone wrong. When faced with the declared need to affirm the inalienable rights to be recognized as dignity in terms of freedom, equality, the right to work, healthcare, education, a life that can be lived with pride, a socio-cultural model that has found in finance a dangerous destructive weapon that affirms the right of the few to the detriment of the many, and we find ourselves in front of a human drama. The elite must, in various respects, respond to the court of history for the damage done to man's future. An international community, as the United Nations should be, must justify its own existence, awareness of even transversal responsibilities that have enabled the affirmation of a socio-cultural model that has shown in the facts that its founding principles are against civil coexistence and respect for the rules. Is this cultural model, according to the prescriptions applied to the various dictators, not to be considered a crime against humanity? The control role of the various financial market regulators has been discarded without any reaction or opposition at least in principle. Quite evident is man's inability to govern himself and to bring under his control a power that is likely to overwhelm him if not regulated and oriented towards the common good.

Globalization and the period of a cultural model that has detached man from his own intimacy shows that the apparatuses and higher-order institutions, without exceptions, push man towards losing his organic bonds and form a man who, without roots, lives by the day with principles of absolute arbitrariness in his choices. In this way, man becomes a victim of a power that is becoming increasingly subtle and insinuated in everyday life, becoming a hostage without even realizing it.

It may be an ungovernable power in nature that responds to superior mechanics, but there cannot be an irresponsible power of man and in this sense the role of power exercised by finance cannot be dissociated from the responsibility of how it is used and by those who determined its purpose. Are those we have in charge of public affairs aware of the responsibilities that have been vested in them? Is this accountability towards society reflected in exercising their functions or is totally disregarded? Do those that make vital decisions for the survival of man as a person have the knowledge needed to carry out this activity and the humility to understand the difficulties that being morally irreprehensible imposes? Are our young people educated in this logic or abandoned to the nothingness of a daily life where it seems they cannot identify themselves in behaviours to imitate? 
All these questions that Romano Guardini put in various ways in his splendid work "The end of the modern world. Power and Responsibility" published in 1956 are always present to demonstrate that thought, which goes deeper and not just a quick glance at the waves, never belies those who read history in the long times that constitute it. "The greater a man's power, the stronger the temptation to take the shortcut of force" (as we see every day, author's note). "The temptation to nullify the individual and his freedom, to ignore both his creative originality and his personal truth; to achieve the desired end simply by force, dismissing what cannot be forced as not worthy of consideration in other words, the temptation to erect a culture on rational and technical foundations alone. To this end, man himself must be considered something "marketable" ("the labor market") something that can be "managed", "laid off or on," "conditioned" from the start to certain ends. Even spiritually man is malleable, once dialectics and mass-suggestion, propaganda and Weltanschauung or historical perspective, even legal testimony are undertaken not with respect for truth, but to support predetermined ends (in turn, subjugated to power, editor's note)" wrote Guardini.

In the end, if our time is the expression of this global drama lived independently of the territories, the beliefs, the different cultures, are we still faced with crimes against human rights for a just existence? It is time to ask ourselves these questions before the final account of history brings to an end the human adventure in this world. If western society is unable to find the right way to respond to the many problems that are strangling it, then from a creative point of view, it has nothing more to say ".

\section{There is a tide in the affairs of men, which taken at the flood, leads on to fortune. Omitted, all the voyage of their life is bound in shallows and in miseries. On such a full sea are we now afloat. And we must take the current when it serves, or lose our ventures. \\ - Shakespeare}

\section{References}

Aristotele (2000) Etica Nicomachea [Nicomachean Ethics]. Bompiani: Milan.

Chomsky N. (2006) Failed States: the Abuse of Power and the Assault on Democracy. Il Saggiatore: Milano.

De Honoré B. (1892) Illusions Perdues [Lost Illusions]. Calmann Lévy: Paris, France.

Galbraih J.K. (1955) The Great Crash: 1929. Houghton Mifflin: Boston.

Guardini R. (1954) The End of the Modern World. Morcelliana: Brescia.

Keynes J. M. (1991) Economic Possibilities for Our Grandchildren. Bollati Boringhieri: Turin.

Keynes J. M. (1923) The End of Laissez Faire. MacMillan Publishers: London. 
Keynes J. M. (1933) Essays in Persuasion. MacMillan: London.

Krugman P. (2009) How Did Economics Get It So Wrong? The N.Y. Magazine.

Pezzani F. (2008) The Lucidity Pact. UBE: Milan.

Pezzani F. (2011) Cooperative Competition. Egea-UBE: Milan.

Pezzani F. (2016) The Nobel Prize for mythical finance and Colombo's egg, Business and Economic Journal. DOI: $10.4172 / 2151-6219.1000267$

Pezzani F. (2016) Independence day and forgotten equality. Business and Economic Journal. D0I: 10.4172/21516219.1000212

Pezzani F. (2017) The gold exchange standard and the magic trap of paper money. Journal of Accounting, Finance and Auditing.

Pezzani F. (2017) Once upon a time in America and the end of the American dream. Journal of Socialomics. DOI: 10.4172/2167-0358.1000208.

Pezzani F. (2017) Society the foundation of the economy. We need a sociocultural revolution. Scholar's Press: Germany.

Posner R. (2010) The crisis of capitalist democracy. Egea-UBE: Milan.

Prigogine I. (1996) La fin des certitudes. Temps, chaos et les lois de la nature. Odile Jacob: Paris.

Putnam R. (2004) Social capital and individualism. Il Mulino: Bologna.

Russell B. (2009) The scientific outlook. Laterza: Rome-Bari.

Schlesinger M. A. Jr. (2010) The age of Jackson. Lee Spilberg: New York.

Sen A. (2010) The theory of moral sentiment. Penguin.

Severino E. (2002) Techne. The roots of violence. Rizzoli: Milano.

Shakespeare William , The complete Works of William Shakespeare, Ed. Barnes \& Noble Inc , 2015.

Sigmund F. (1971) The Discomforts of Civilization. Bollati Boringhieri: Turin.

Sigmund F. (1971) The Future of Illusion. Boringhieri: Turin.

Sorokin P. (1941) Social and cultural dynamics. Utet: Turin.

Sorokin P. (1941), The Crisis of our age. EP Button \& Co: New York.

Toynbee A.J. (1949) Civilization on trial. Bompiani: Milan.

Toynbee A. J. (1977) Mankind and mother earth. Garzanti: Milan.

Vico G. (1725), La scienza nuova, [The New Science]. Napoli.

Zygmunt B. (2005) Liquid Life. Laterza: Bari. 